\title{
Validation of FE models of bullet impact on high strength steel armors
}

\author{
P. Siriphala, T. Veeraklaew, W. Kulsirikasem \\ \& G. Tanapornraweekit \\ Defence Technology Institute (Public Organization), \\ Bangkok, Thailand
}

\begin{abstract}
This paper presents a validation of a finite element (FE) model to predict the performance of high strength steel armor against the penetration from M193 bullets. A series of perforation tests were performed on an Armox 600T steel plate. The velocity of bullet was measured using an electronic measuring system. A propellant weight of the bullet was calibrated before the test so as to obtain a desired bullet velocity which meets the test standard. The test results show that only one shot from all tests penetrated a $7 \mathrm{~mm}$ of Armox 600T. Generally, a $7 \mathrm{~mm}$ of Armox $600 \mathrm{~T}$ is sufficient to withstand the threat level specified in the test standard. An Eulerian FE solver was employed to simulate behavior of a bullet impact. A series of FE analyses varying Eulerian cell sizes were performed in this study so as to obtain converge results. It is found that an element size of $0.035 \mathrm{~mm}$ is required for this type of modeling in order to capture a realistic interaction between bullet and armor plate. The FE results of the model with $0.035 \mathrm{~mm}$ of cell size conform to the test results in terms of crater depth and crater diameter on the test armors.
\end{abstract}

Keywords: bullet, impact, crater, Armox 600T, finite element.

\section{Introduction}

In order to evaluate a resistance of a ballistic defeat material for an army vehicle, real bullet impact tests are necessary to be performed. For some instances, where actual tests are not possible, a finite element technique is employed to predict the behavior of this bullet impact event. This study aims to verify the efficacy of a high strength steel, Armox 600T, against high velocity impact of a M193 bullet. 
A series of repeat tests were conducted on a clamped test plate. Before the real tests, the propellant weight of bullet was calibrated so as to obtain the bullet velocity which meets the protection level type IV specified in [1]. Apart from the experiment, this study also aims to verify an FE model employed to predict the resistance of an armor plate against bullet impact. An Eulerian FE solver where the material is able to flow through structure grids was employed for the simulation of bullet impact on an armor. This type of computation is suitable to handle the model with a severe distortion [2].

\section{Experimental program}

A $300 \times 300 \mathrm{~mm}$ of Armox $600 \mathrm{~T}$ steel plate was tested against impact of a $56 \mathrm{gr}$ of M193 bullet [3]. A thickness of the test plate is $7 \mathrm{~mm}$. A total of five shots were originally planned for the tests, however, only four shots were performed. The location of each shot on the test plate is approximately $75 \mathrm{~mm}$ from the edge of the test plate. The bullet velocity was measured for each test as shown in table 1 . The test plate was clamped on its two edges to the test frame.

Table 1: $\quad$ Bullet velocity for each test shot.

\begin{tabular}{|c|c|}
\hline Shot No. & Measured bullet velocity $(\mathrm{m} / \mathrm{s})$ \\
\hline 1 & 967.63 \\
\hline 2 & 969.37 \\
\hline 3 & 967.48 \\
\hline 4 & 969.41 \\
\hline
\end{tabular}

\section{Experimental results}

The Armox 600T test plate was able to stop M193 bullets in the first three shots. However, the last shot penetrated through the test plate. This might be the consequence of the variation in the material properties of the test plate. However, the shapes and sizes of craters resulted from test shot 1 to test shot 3 were identical. Test shot number 4 perforated the test plate in a shear plugging mode. It is noted that this failure mode produce smaller crater diameter compared to those resulted from test shot 1 to test shot 3 .

Fig. 1 shows the test plate after the tests. The number on the test plate indicates shot numbers. The close up of the craters are shown in fig. 2. Crater shape of each test shot was captured using a 3D scanner. The 3D surfaces obtained from a 3D scanner were cut every $0.2 \mathrm{~mm}$ so as to obtain crater profiles. The crater depth and diameter were measured from the selected crater profile which presents the maximum crater depth and diameter as illustrated in fig. 3. The measured crater sizes and depths are summarized in table 2. 


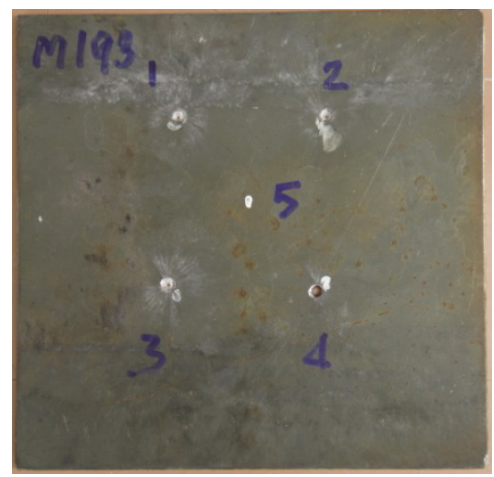

Figure 1: $\quad$ Armox 600T plate after the tests.

a) Shot 1
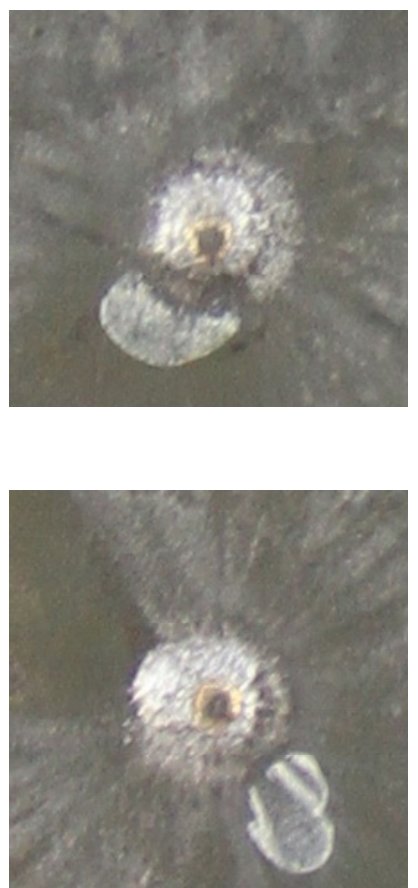

c) Shot 3 b) Shot 2
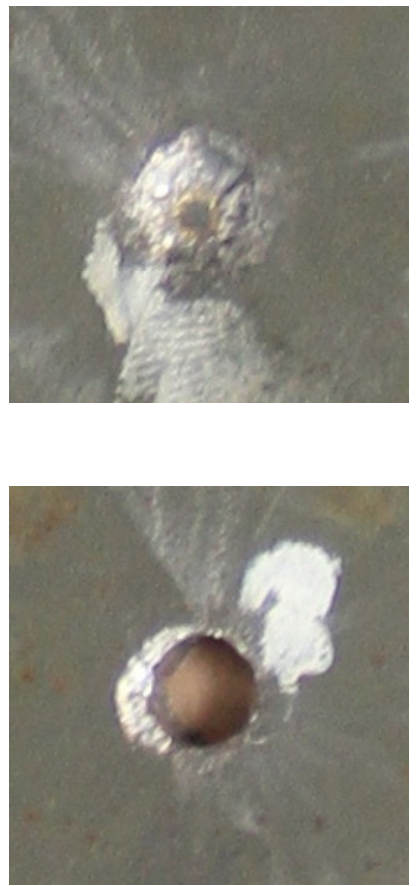

d) Shot 4

Figure 2: $\quad$ Craters of the test plate for shots 1 to 4 . 
78 Structures Under Shock and Impact XII

Table 2: $\quad$ Measured depth and crater diameter.

\begin{tabular}{|l|c|c|}
\hline Shot & Average depth (mm) & Average diameter $(\mathrm{mm})$ \\
\hline 1 & 0.898 & 8.689 \\
\hline 2 & 1.134 & 14.871 \\
\hline 3 & 0.900 & 8.908 \\
\hline 4 & Penetration & 6.210 \\
\hline
\end{tabular}
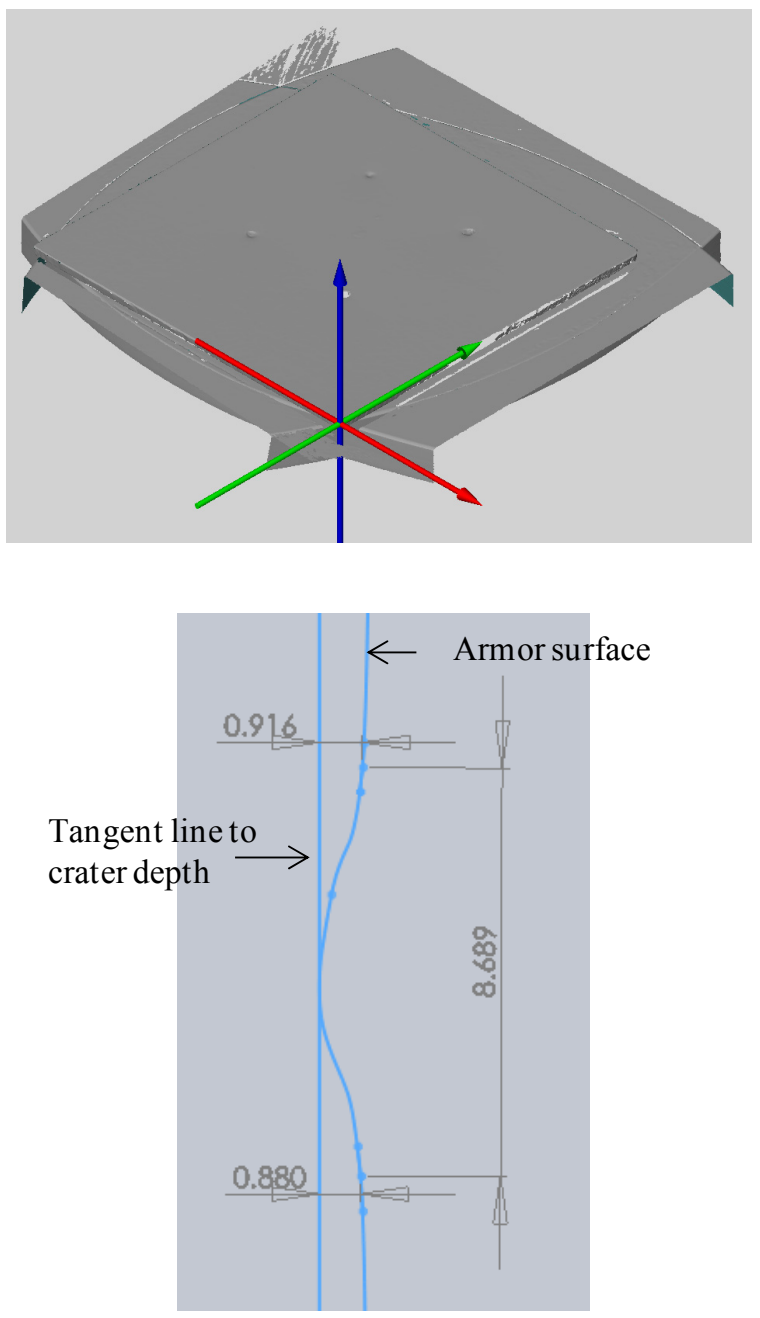

Figure 3: Measurement of crater depth and diameter obtained from a 3D scanner. 


\section{FE analysis}

Apart from ballistic resistance tests, this research also performs finite element (FE) analyses employed to simulate a behavior of bullet impact on an armor plate and to predict the ballistic resistance of an armor plate. In addition, the FE analysis is able to predict the crater shape, crater diameter and crater depth. In this research, the explicit FE code, AUTODYN, was employed to simulate an interaction between bullet and armor plate.

The high velocity impact problem can be modeled using Euler solver available in Autodyn. Preece and Berg [4] employed an Eulerian solver to simulate shape and dimension of craters resulted from a 338 Winchester Magnum on steel armor. The simulation results match well with the test results. Therefore, this research also employs an Eulerian solver to model an impact of M193 bullet on Armox 600T plate.

Fig. 4 presents shape and dimension of M193 bullet. Bullet jacket is made of copper whilst bullet core is made of lead. The model was set up in 2D
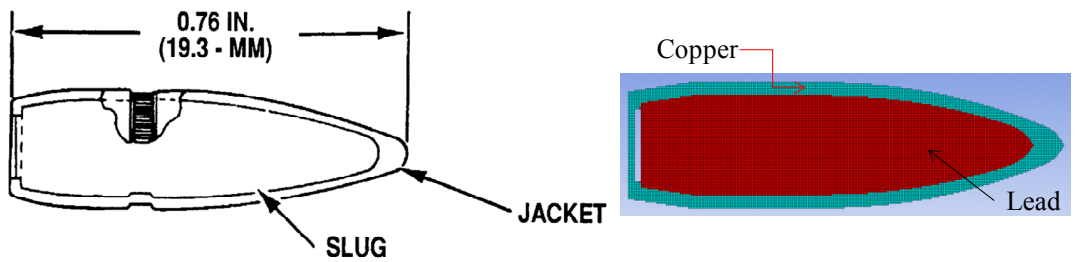

Figure 4: $\quad$ Shape, dimension [3] and FE model of M193 bullet.

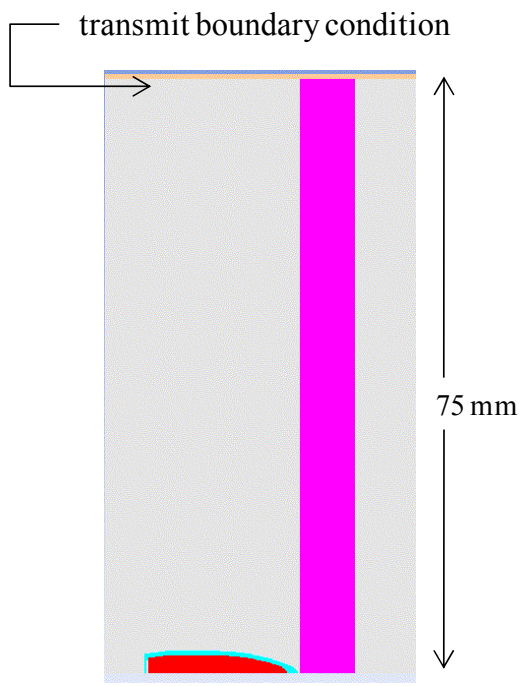

Figure 5: $\quad$ Set up of FE model. 
axisymetric in which a transmit boundary condition was applied at the edge of the modeled amour plate as shown in fig. 5. An initial velocity of $968 \mathrm{~m} / \mathrm{s}$ was applied to the modeled bullet. Six FE analyses varying the Eulerian cell size from $0.035 \mathrm{~mm}$ to $0.15 \mathrm{~mm}$ were performed in order to obtain converge results. The number of elements for a modeled armor plate was varied from 23,000 to 428,400 elements according to a variation in cell sizes.

Steinberg Guinan strength model and shock EOS were employed to model copper and lead for a modeled M193 bullet. The default parameters of Steinberg Guinan strength model and shock EOS for copper and lead were adopted to model these bullet compositions. A high strength steel armor plate, Armox 600T, was represented using Johnson Cook constitutive model.

The parameters for Johnson Cook strength model presented in Nilsson [5] were adopted in this study and listed in table 3 . It is noted that material testing of an Armox 600T plate was not conducted in this research.

Table 3: Johnson Cook constitutive parameters for Armox 600T.

\begin{tabular}{|c|c|}
\hline Parameters & Values \\
\hline $\mathrm{A}, \mathrm{GPa}$ & 1.58 \\
\hline $\mathrm{B}, \mathrm{GPa}$ & 0.958 \\
\hline $\mathrm{n}$ & 0.175 \\
\hline $\mathrm{C}$ & 0.00877 \\
\hline $\mathrm{m}$ & 0.712 \\
\hline
\end{tabular}

\section{FE results}

A series of FE simulation were performed varying the Eulerian mesh sizes. This research focuses on the crater depth and crater diameter of Armox 600T armor plate resulted from an impact of M193 bullet. Fig. 6 presents crater shapes on the modeled armor plate for each FE analysis. It can be seen from fig. 6 that the size and shape of crater depend on the number of elements or the FE mesh size.

The simulated crater depth of each analysis varying the cell sizes is presented in fig. 7. It can be seen that the simulated crater depth is larger than those obtained from the measurement. Fig. 8 presents a comparison of the analyzed crater diameters to the measurement. The crater diameter obtained from the FE model with the smallest cell size is smaller than that of crater 2 but still larger than that of an average measured diameter. It can be seen from fig. 7 and fig. 8 that the FE results converge on the FE model with the smallest cell size, $0.035 \mathrm{~mm}$.

The predicted crater depth does not agree rather well compared to the test results. The input parameters for the material models employed in the analyses might not represent their actual properties as the material tests were not performed in this study. This might cause a difference in crater depth and crater diameter compared to the test results. In addition, it is possible that the test might show some variations in the test results. The evidence in variation of the test results is that the test shot number 4 showed the penetration of the test plate whilst the test plate is able to withstand the first three shots. 
a) 428400 elements

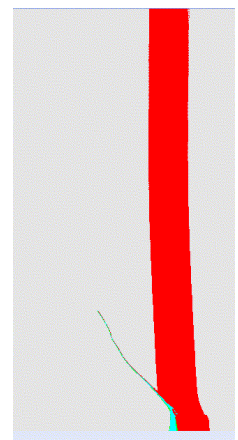

d) 68560 elements

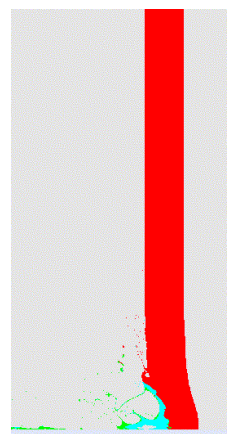

b) 210000 elements

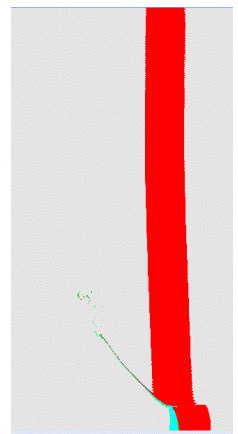

e) 36018 elements

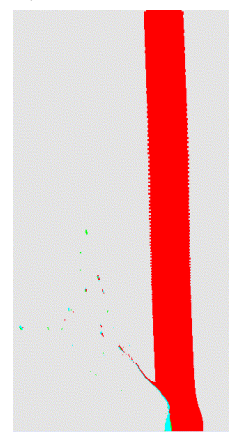

c) 107100 elements

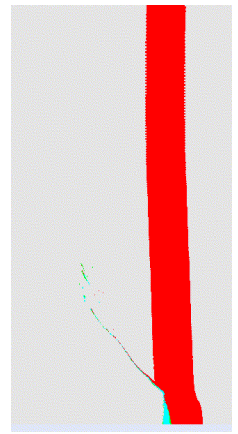

f) 23000 elements

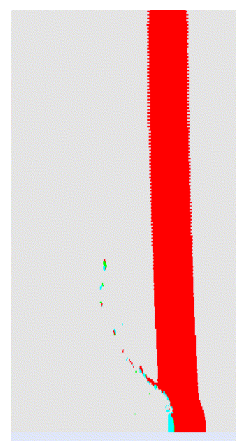

Figure 6: Crater shapes obtained from all FE analyses.

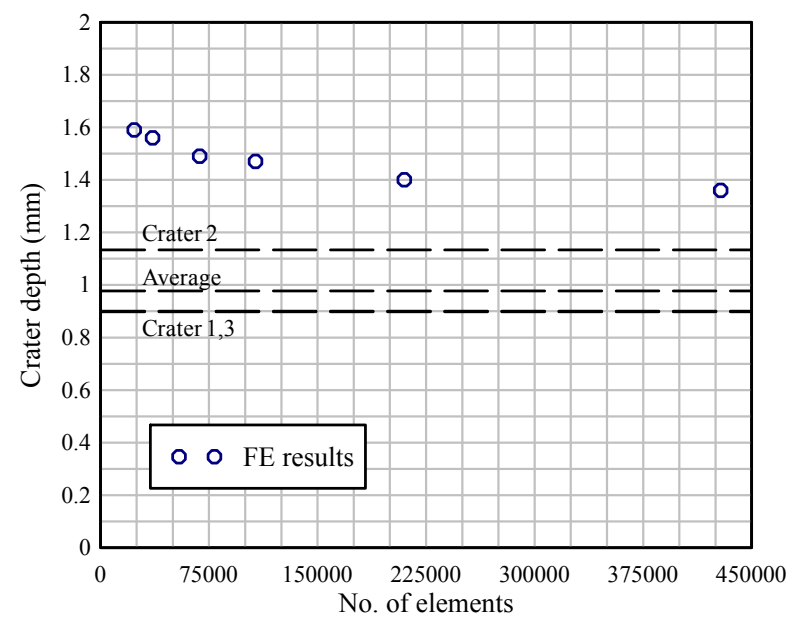

Figure 7: Comparison of crater depths between $\mathrm{FE}$ results and 3D scan measurement. 


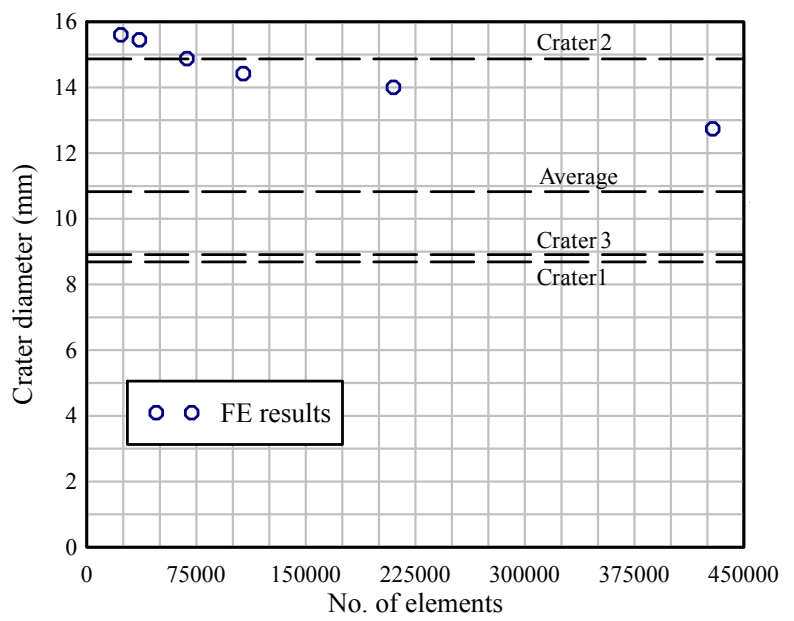

Figure 8: Comparison of crater diameters between FE results and 3D scan measurement.

\section{Conclusion}

This paper presents both the experimental and numerical studies on the behavior of M193 bullet on an Armox 600T armor. The experiment shows that a $7 \mathrm{~mm}$ of Armox 600T is able to withstand impacts of M193 bullet with an average initial velocity of $968 \mathrm{~m} / \mathrm{s}$. The depth and diameter of craters resulted from bullet impacts in the first three shots were identical. However, the last shot penetrated the test plate. These test results showed some variation in the tests which might be the results from an inhomogeneous of the test plate. Apart from the experimental studies, this research presents a validation of the FE model using Autodyn code employed to simulate bullet impacts on an Armox 600T plate. The FE analyses seem to over predict crater depth, however, the analyses reasonably predict crater diameter. It should be noted that there were also some variation in the test results. Moreover, the FE simulation was based on the constitutive parameters reported in Nilsson [5] and the default values suggested by the FE code. From this study, it is rational to rely on the FE results in case an efficacy of an armor plate is required to evaluate.

\section{References}

[1] Test Methods for Ballistic Defeat Materials - MIL-STD-3038; Department of Defense.

[2] Zukas, J. A., Introduction to Hydrocodes, Elsevier, 2004.

[3] Army Ammunition Data Sheets - Small Caliber Ammunition FSC 1305 TM 43-0001-27; Department of the Army. 
[4] Preece, D. S. and Berg, V. S., Bullet impact on steel and kevlar/steel armor: Computer modeling and experimental data, ASME Conference Proceedings - Pressure Vessels and Piping Conference, San Diego, CA., pp. 207-212, 2004.

[5] Nilsson, M., Constitutive model for Armox 500T and Armox 600T at low and medium strain rates, FOI-R-1068-SE, 2003. 